\title{
Actual Status of Healthy Lifestyle Habits of Public Health Nurses in Japan
}

\author{
Yoko Nishida1, Keiko Koide'2, Reiko Okamoto3 ${ }^{3}$, Saori Iwamoto 4 , \\ Kayoko Goda', Hiroko Seki' ${ }^{6}$, Yukiko Sugimoto ${ }^{6}$
}

\author{
${ }^{1}$ Department of Nursing Faculty of Health and Welfare Kawasaki University of Medical Welfare, Okayama, Japan \\ ${ }^{2}$ Faculty of Education, Shitennoji University, Osaka, Japan \\ ${ }^{3}$ Division of Health Sciences, Graduate School of Medicine, Osaka University, Osaka, Japan \\ ${ }^{4}$ Graduate School of Biomedical Sciences, Tokushima University, Tokushima, Japan \\ ${ }^{5}$ Faculty of Nursing and Rehabilitation, Konan Women's University, Hyogo, Japan \\ ${ }^{6}$ Former Graduate School of Health Sciences, Okayama University, Okayama, Japan \\ Email: y_nishida@mw.kawasaki-m.ac.jp
}

How to cite this paper: Nishida, Y., Koide, K., Okamoto, R., Iwamoto, S., Goda, K., Seki, H. and Sugimoto, Y. (2018) Actual Status of Healthy Lifestyle Habits of Public Health Nurses in Japan. Health, 10, 189203.

https://doi.org/10.4236/health.2018.102016

Received: December 29, 2017

Accepted: February 8, 2018

Published: February 11, 2018

Copyright (C) 2018 by authors and Scientific Research Publishing Inc. This work is licensed under the Creative Commons Attribution International License (CC BY 4.0).

http://creativecommons.org/licenses/by/4.0/

\section{Open Access}

\begin{abstract}
Background: The public health nurse should make efforts to keep his/her own mental and physical health good, which is the professional responsibility. However, a variety of challenging issues have been pointed out with regard to well-being of healthcare professionals. Public health nurses are likely to face some difficulties in their habits of leading healthy lifestyles. The purpose of this study was to identify how Japanese public health nurses actually live their healthy lives. Methods: This study covered 1725 public health nurses in the Chugoku/Shikoku Region. We conducted an anonymous self-completed questionnaire survey. As basic attributes, the following 6 categories were set. The health practice indices used in this research consisted of the 7 practices of Breslow's Health Practice Index (B-HPI), the Morimoto's 8 practices, and 6 practices related to lifestyle habits that have been developed independently by the authors of this research (Health Lifestyle Index (HLI)), that is, 16 practices in total. The study plan was approved by the Ethics Committee of Okayama University. Results: We analyzed the 960 (55.7\%) valid responses. This survey has demonstrated that the healthy lifestyle practices of public health nurses are generally good. However, there were some practices such as eating between meals, having little physical activity, and not having a good rest/sleep, that need to be improved. None of the assessment tools correlated with the length of experience. Conclusions: This survey has clarified that the healthy lifestyle practices of public health nurses did not correlated with their length of experience, indicating that the healthy lifestyle practices are not intensified by the accumulated career experience as public health nurses.
\end{abstract}




\section{Keywords}

Public Health Nursing, Related Factors, Health Practice, Breslow's Health Practice

\section{Introduction}

\section{Background and Purpose of Research}

Nursing professionals including public health nurses should comply with the Code of Ethics for Nurses adopted by the International Council of Nurses (ICN) and the Ethical Code for Nursing Professionals established by the Japanese Nursing Association (JNA). Both the codes describe that the nursing professional is required to endeavor to maintain his/her own mental and physical health in good condition such that the ability to provide high quality nursing care is not compromised [1] [2]. It is therefore considered that the public health nurse should make efforts to keep his/her own mental and physical health good, which is the professional responsibility.

A preceding research [3] has demonstrated that the greater primary care physicians are accustomed to getting exercise, the more they are proactive in guiding their patients to take exercise. This finding suggests that healthcare professionals' desirable personal health habits have favorable impacts on their health guidance given to their care receivers. The public health nurse is a person who is entitled under licensure from the national government to use the title of Public Health Nurse and provide health guidance as a profession (Article 2 of the Japanese Act on Public Health Nurses, Midwives, and Nurses) such that public health nurses are expected to focus on lifestyles of care receivers and to help them change their behavior to improve their lifestyle habits. It is therefore desirable that public health nurses have favorable health practices so as to ensure the quality of care they provide.

However, a variety of challenging issues have been pointed out with regard to well-being of healthcare professionals. The survey performed by the Japan Medical Association (JMA) on hospital-employed physicians revealed the following: $41.1 \%$ of the survey subjects slept for less than 6 hours/day on an average; $53.3 \%$ of them did not consult other persons about their own ill health; $8.7 \%$ of them were in the state of depression as scored by 11 points or more according to the Japanese Version of QIDS-SR-J; 13.6\% of them were smokers; and $62.1 \%$ of them did not exercise so hard as making them sweat. These survey results have demonstrated that several items including sleep, exercise, smoking, and mental health need to be adequately addressed [4]. For nurses also, it has been demonstrated that they suffer from mental health-related issues, which may be caused by occupational stress, and face challenges with respect to lifestyle habits including smoking and alcohol drinking [5]. In reality, even healthcare professionals having a good stock of knowledge about diseases and their prevention cannot have desirable lifestyle habits to maintain their good health, because the technic- 
al levels of their responsibilities have increased and they are very busy.

The circumstances in which public health nurses work also have recently been diversified and complicated in terms of health-related issues; they need to handle health risk management responsibilities for disasters, infections, and abuse, and in addition, manage lifestyle-related diseases including cancer and diabetes. Along with these changes, their duties have increased and extended to the areas of medical care and welfare. The survey on the awareness of public health nurses regarding the current status [6] has supported the fact that the cases in which they require assistance and their duties have become complicated and more challenging. As in the physicians and nurses described above, public health nurses are likely to face some difficulties in their habits of leading healthy lifestyles.

However, as far as we searched relevant publications in "Ichushi-Web", a Japanese leading and exhaustive bibliographic database of Japanese biomedical literature, using the key words of "public health nurse", "life", and "actual status" for a recent 10-year period, we found no research that elucidated the actual status of public health nurses' health practices. Under these circumstances, we conducted this research to identify how Japanese public health nurses actually live their healthy lives. This research is of significance in the following two points: 1) public health nurses can review their personal health habits by reference to the clarified actual status as basic data so as to explore the ideal health management for individuals and for the professional group; and 2) investigation of the actual status on public health nurses' lifestyle habits and factors inhibiting these habits provides suggestions about the ideal way of giving health guidance to their care receivers.

\section{Research Method}

\subsection{Research Design}

This research is a cross-sectional, fact-finding survey to explore relationships.

\subsection{Subjects Surveyed}

The survey included 1725 subjects who accounted for about half the full-time public health nurses belonging to the municipal governments of 9 prefectures making up the Chugoku and Shikoku Regions in Japan as well as to all municipalities located in these prefectures. The reason for our choosing this region is because major natural disasters had not recently occurred in this region, which have kept the subjects' lifestyles almost unchanged.

\subsection{Survey Method}

Anonymous self-administered questionnairing was performed by regular mailing. The questionnaires, together with a letter of request to cooperate in this survey, written information about ethical considerations, questionnaire, and return envelope, were sent to the representative public health nurses of the facili- 
ties in which the subjects under survey worked. We requested in writing that the representatives unbiasedly distribute the questionnaires to half the full-time public health nurses in their facilities. The survey period ran from December 2013 to January 2014 for the Chugoku Region and December 2014 to January 2015 for the Shikoku Region.

\subsection{Survey Items}

1) Basic attributes

As basic attributes, the following 6 categories were set: gender, age, years of career experience as a public health nurse (hereinafter to be referred to as the "length of experience"), the main body that establishes the facility in which the surveyed subject works, educational institutions at which the subjects studied public health nursing, and latest academic background.

2) Health practice indices

The health practice indices used in this research consisted of the 7 practices of Breslow's Health Practice Index (B-HPI) that have frequently been used both inside and outside Japan [7] [8], the Morimoto's 8 practices (M-HPI, note that 5 practices of the 8 are the same as those of B-HPI), and 6 practices related to lifestyle habits that have been developed independently by the authors of this research (Health Lifestyle Index (HLI)), that is, 16 practices in total [9] [10]. HLI focuses on the health awareness and behavior during daily living activities and therefore, consists of the following 6 practices representing major health habits: eating habits, physical activities, rhythm of a daily life, awareness of prevention against diseases, utilization of health-related information, and social relations. The practices of HLI were set as a result of thorough discussion by the researchers of this study. For B-HPI and M-HPI, each subject was asked whether or not the practice questioned was applicable to him/herself ( 1 point when applicable, and 0 point when not applicable). For HLI, each subject was instructed to select one of the 4 answers that was applicable to him/her (4 points when applicable, 3 points when slightly applicable, 2 points when not greatly applicable, and 1 point when not applicable). The Cronbach's coefficient alpha for HLI we calculated was 0.74 , indicating an acceptable level of internal consistency. We therefore decided to analyze total scores also.

\subsection{Method of Analysis}

1) Basic attributes

For each parameter of the basic attributes, the number and proportion (\%) of subjects were determined. For age and length of experience, means and standard deviations were also calculated.

2) Actual status of healthy lifestyle practices

Means and standard deviations were calculated for total scores of individual assessment tools. Subsequently, the 4 groups in the category of length of experience were compared by one-way analysis of variance and by the Dunnett's 
method for multiple comparisons. Correlation between the length of experience and the total score of each assessment tool was analyzed, and identified characteristics were compared. For each of all 16 practices employed for this research, the number and proportion (\%) of subjects who gave an answer of "applicable" were calculated and the obtained data were analyzed in cross-tabulations with the length of experience, followed by the Chi-square test. For HLI, the answers were organized into 2 groups, that is, one group of "applicable" consisting of "applicable" and "slightly applicable", and the other of "not applicable" consisting of "not greatly applicable" and "not applicable", for the purpose of analysis. The length of experience was divided into the following 4 groups in accordance with the method described in a preceding research [11]: a group of $\leq 5$ years, one of $\geq 6$ years to $\leq 15$ years ( 6 - 15 years), one of $\geq 16$ years to $\leq 25$ years ( 16 - 25 years), and one of $\geq 26$ years. SPSS Statistics version 23 was used for statistical analysis, with a significance level of 0.05 .

\subsection{Ethical Considerations}

As ethical considerations, we gave written explanation to the survey subject and the head of the institution in which he/she works, about the purpose and significance of this survey, the fact that a subject's cooperation in this survey was voluntary, the actions taken to protect a subject's privacy and personal information, the method to retain obtained data, how the research results will be published, possible burdens to be imposed to subjects, and any other relevant matters. The individual respondents were asked to use the return envelope to send back the completed questionnaire to the researchers of this survey. We documented that when a public health nurse returned his/her administered questionnaire, the nurse gave us his/her informed consent to cooperation in this survey. The conduct of this research was approved by the Research Ethics Review Committee at the Department of Nursing, Graduate School of Health Sciences, Okayama University (M15-07, September 30, 2015).

\section{Results}

\subsection{Collection of Questionnaires}

A total of 982 questionnaires were collected (with a collection rate of 56.9\%) and 960 of the 982 were valid (with a valid response rate of 55.7\%). The attributes of survey subjects and the characteristics of the Chugoku/Shikoku Region are shown in Table 1. The mean age was $41.8 \pm 10.41$ years, with a range from 22 to 60 years. The vast majority of subjects were women.

\subsection{Actual Status of Public Health Nurses' Healthy Lifestyle Practices}

1) Total scores for healthy lifestyle practices

The mean \pm standard deviation (range) for the total score of each assessment tool was $4.9 \pm 1.05(2-7)$ for B-HPI, $5.7 \pm 1.38(1-8)$ for M-HPI, and $5.3 \pm 1.04$ 
Table 1. Attribute $(\mathrm{N}=960)$.

\begin{tabular}{|c|c|c|c|}
\hline \multicolumn{2}{|r|}{ Items } & \multirow{2}{*}{$\begin{array}{l}\mathrm{N} \\
16\end{array}$} & \multirow{2}{*}{$\begin{array}{c}\% \\
1.7\end{array}$} \\
\hline & male & & \\
\hline \multirow[t]{5}{*}{ Sex } & female & 935 & 97.4 \\
\hline & blank & 9 & \\
\hline & & \multicolumn{2}{|c|}{$41.8 \pm 10.41(22-60)$} \\
\hline & Twenties & 163 & 17.2 \\
\hline & Thirties & 236 & 24.8 \\
\hline \multirow[t]{5}{*}{ Age } & Forties & 268 & 28.2 \\
\hline & Fifties or more & 283 & 29.8 \\
\hline & blank & 10 & \\
\hline & & \multicolumn{2}{|c|}{$17.8 \pm 10.58(1-38)$} \\
\hline & 5 years or less & 179 & 18.6 \\
\hline \multirow[t]{4}{*}{ Years of PHN experience } & $6-15$ years & 235 & 24.5 \\
\hline & $16-25$ years & 267 & 27.8 \\
\hline & 26 years or more & 279 & 29.1 \\
\hline & Prefectures & 236 & 24.6 \\
\hline \multirow[t]{3}{*}{ Place of work } & Government-ordinance-designated cities & 144 & 15.0 \\
\hline & Cities & 580 & 60.4 \\
\hline & Vocational schools (one year course) & 545 & 56.8 \\
\hline \multirow{4}{*}{$\begin{array}{l}\text { Educational institutions at } \\
\text { which the subjects studied } \\
\text { public health nursing }\end{array}$} & Junior colleges & 77 & 8.0 \\
\hline & Colleges or universities & 302 & 31.5 \\
\hline & Vocational schools (Integrated curriculum) & 36 & 3.7 \\
\hline & Vocational schools & 456 & 47.5 \\
\hline \multirow[t]{2}{*}{ latest academic background } & Junior colleges & 152 & 15.8 \\
\hline & Colleges or universities/graduate schools & 352 & 36.7 \\
\hline
\end{tabular}

Mean value \pm standard deviation (range) for Age and Years of PHN experience (except where data are not available). The characteristics of the Chugoku/Shikoku Region: It consists of 9 prefectures, the population of which accounts for approximately $10 \%$ of Japan. Cities in this region greatly vary in size, from large cities with more than 1 million people to depopulated areas. It is a region of geographic diversity, with coastal areas, islands, and mountain areas. There exists a variety of industries including agriculture, forestry, fishery, mining, manufacturing, construction, and services.

(0 - 6) for HLI. The mean scores reached $70 \%$ of full marks in all assessment tools. In particular, the mean score for HLI was very high as indicated by the $90 \%$ of full marks.

For HLI, the total score calculated for each of the 4 groups in the category of length of experience was significantly lower in the group of $\leq 5$ years than in the group of $6-15$ years $(p<0.05)$ and in the group of $\geq 26$ years $(p<0.001)$. For B-HPI and M-HPI, no differences were noted among the groups in this category (Table 2, Figure 1-3). 
2) Actual status of practice-specific health habits

In 11 practices of the 16 employed for this research, more than about $80 \%$ of respondents had favorable lifestyle habits.

The desirable health practice performed by the largest number of respondents, i.e., 935 (97.4\%), was "Do not smoke". The desirable health practices performed by more than $90 \%$ of subjects were "Always take care not to catch a cold" by 917 respondents (95.5\%), "Active in adopting useful health information in daily lifestyle" by 904 respondents ( $94.2 \%)$, "Moderate or no alcohol consumption" by 896 respondents (93.3\%), and "Have daily breakfast" by 893 respondents

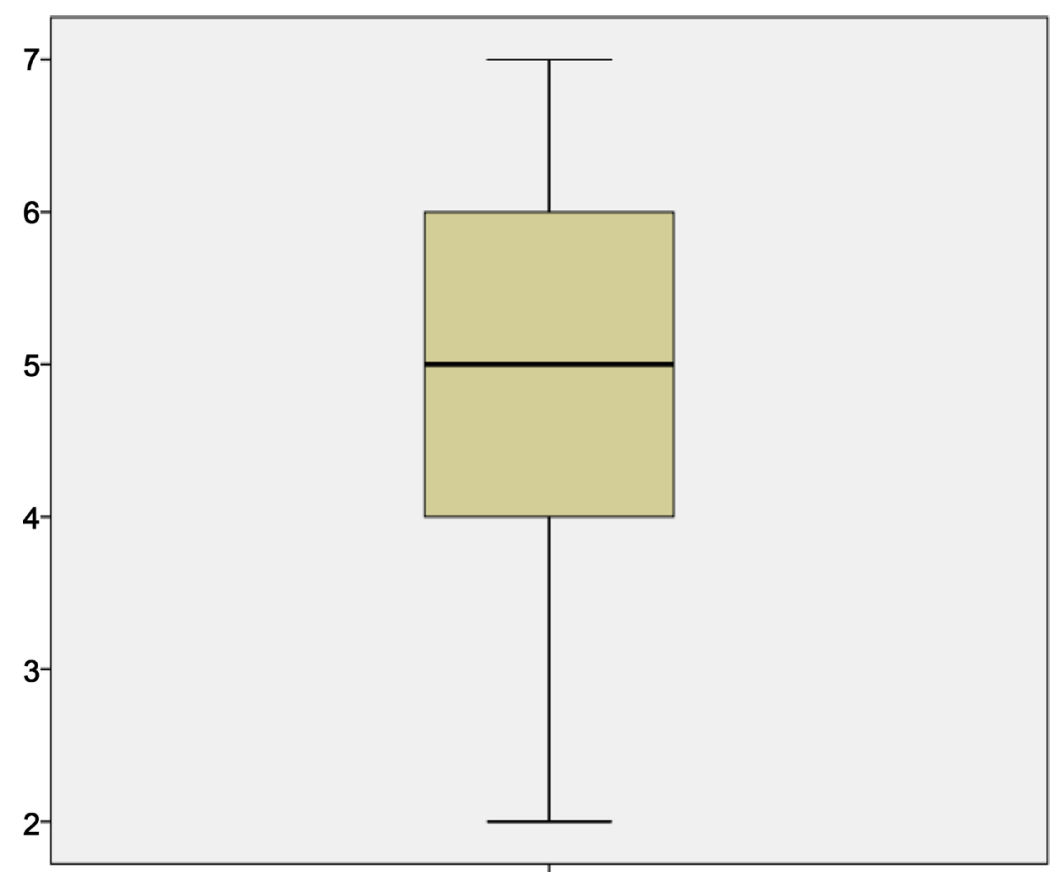

Figure 1. B-HPI score box plot chart.

Table 2. Daily lifestyle scores analyzed by years of experience $(\mathrm{N}=960)$.

\begin{tabular}{|c|c|c|c|c|c|c|c|c|c|c|}
\hline & \multirow[b]{2}{*}{$\mathrm{n}$} & \multicolumn{3}{|c|}{ B-HPI } & \multicolumn{3}{|c|}{ M-HPI } & \multicolumn{3}{|c|}{ HLI } \\
\hline & & $\begin{array}{c}\text { Mean value } \pm \\
\text { standard deviation } \\
\text { (range) }\end{array}$ & $\begin{array}{c}p \\
\text { value }^{\star}\end{array}$ & $\begin{array}{c}\text { multiple } \\
\text { comparison } \\
\star *\end{array}$ & $\begin{array}{c}\text { Mean value } \pm \\
\text { standard } \\
\text { deviation (range) }\end{array}$ & $\begin{array}{c}p \\
\text { value }^{\star}\end{array}$ & $\begin{array}{c}\text { multiple } \\
\text { comparison } \\
\star \star\end{array}$ & $\begin{array}{c}\text { Mean value } \pm \\
\text { standard deviation } \\
\text { (range) }\end{array}$ & $\begin{array}{c}p \\
\text { value }^{*}\end{array}$ & $\begin{array}{c}\text { multiple } \\
\text { comparison } \\
* *\end{array}$ \\
\hline Total & 960 & $4.9 \pm 1.05(2-7)$ & & & $5.7 \pm 1.38(1-8)$ & & & $5.3 \pm 1.04(0-6)$ & & \\
\hline \multicolumn{11}{|c|}{ Years of PHN experience } \\
\hline $\begin{array}{c}5 \text { years or } \\
\text { less }\end{array}$ & 179 & $5.1 \pm 1.09(2-7)$ & 0.089 & n.s. & $5.7 \pm 1.48(2-8)$ & 0.426 & n.s. & $5.1 \pm 1.20(0-6)$ & $<0.001$ & 70.020 \\
\hline $6-15$ years & 235 & $5.0 \pm 0.99(2-7)$ & & & $5.8 \pm 1.30(1-8)$ & & & $5.4 \pm 0.90(1-6)$ & & 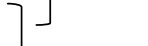 \\
\hline $\begin{array}{c}16-25 \\
\text { years }\end{array}$ & 267 & $4.8 \pm 1.09(2-7)$ & & & $5.6 \pm 1.45(2-8)$ & & & $5.3 \pm 1.13(0-6)$ & & \\
\hline $\begin{array}{c}26 \text { years or } \\
\text { more }\end{array}$ & 279 & $4.9 \pm 1.04(2-7)$ & & & $5.6 \pm 1.33(2-8)$ & & & $5.3 \pm 0.90(0-6)$ & & $<0.001$ \\
\hline
\end{tabular}

${ }^{*}$ one way ANOVA. ${ }^{* *}$ multiple comparison by Dunnett's test. 


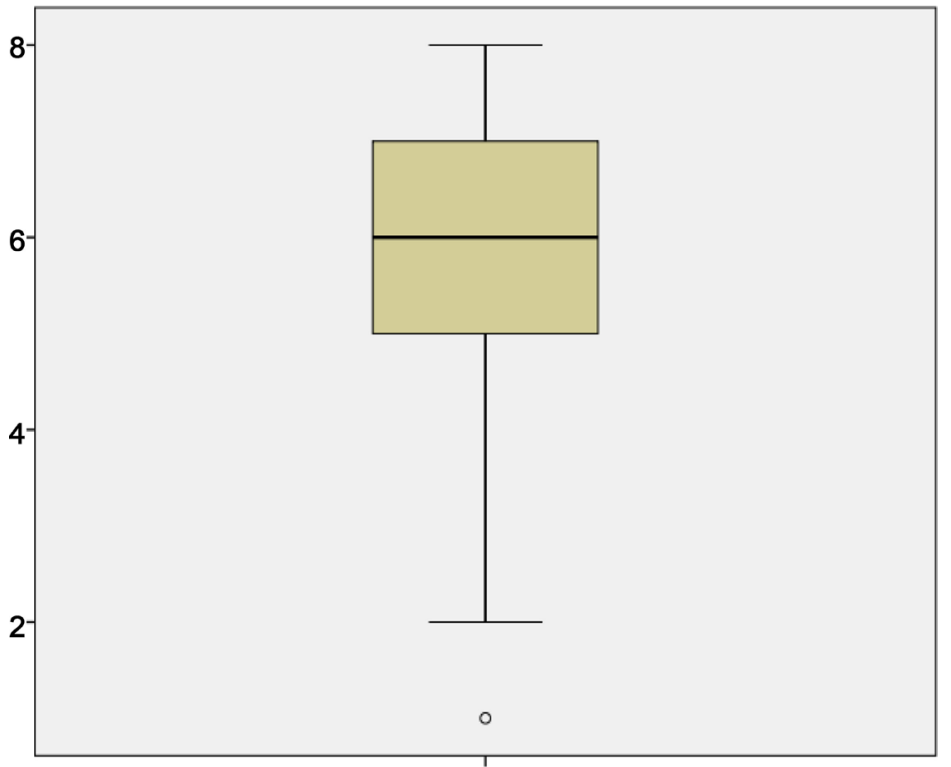

Figure 2. M-HPI score box plot chart.

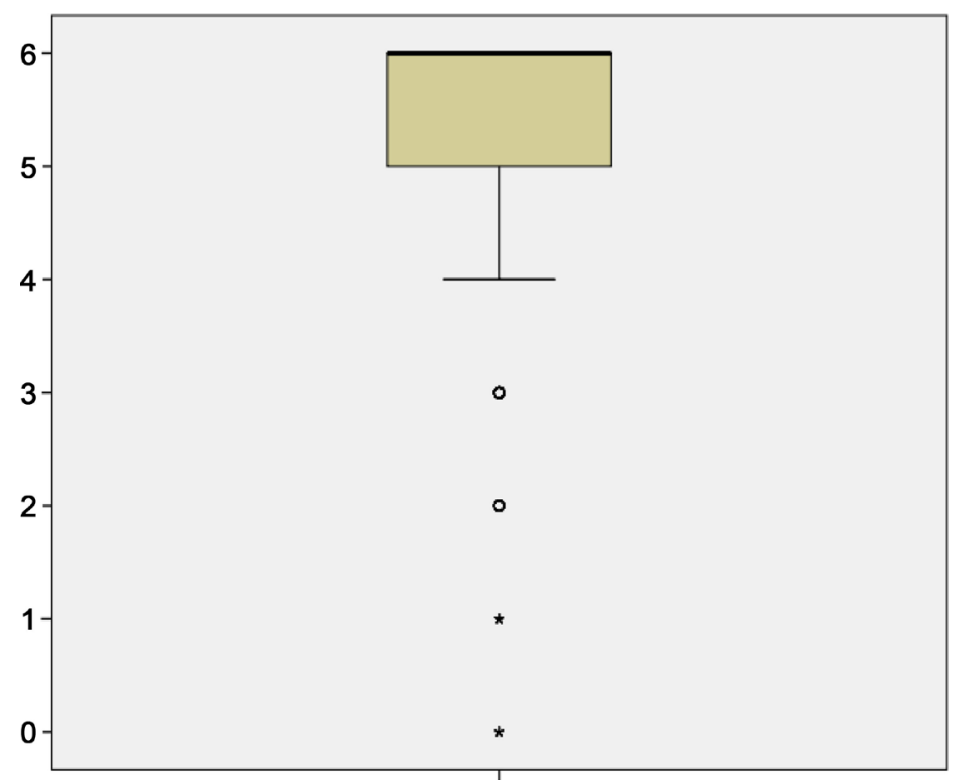

Figure 3. HLI score box plot chart.

(93.0\%) in the descending order.

On the other hand, the desirable health practice performed by the smallest number of respondents, i.e., 177 (18.4\%), was "Do not eat between meals", followed by "Regular exercise" by 383 respondents (39.9\%), "Do not feel much subjective stress" by 408 respondents (42.5\%), "Do not work over 9 hours per day" by 467 respondents (48.6\%), and "Get enough sleep (7 - 8 hours)" by 619 respondents (64.5\%) (Table 3$)$.

Comparison among the 4 groups in the category of length of experience revealed that the desirable health practice of "Have daily breakfast" was performed in a significantly smaller number of respondents in the group of $\leq 5$ years than 
Table 3. Daily lifestyle of public health nurses $(\mathrm{N}=960)$.

\begin{tabular}{|c|c|c|c|}
\hline & Health practice indices & $\mathrm{N}$ (yes) & $\%$ \\
\hline \multirow[t]{7}{*}{ B-HPI } & 1) Do not smoke* & 935 & 97.4 \\
\hline & 2) Moderate or no alcohol consumption* & 896 & 93.3 \\
\hline & 3) Have daily breakfast* & 893 & 93.0 \\
\hline & 4) Maintain desirable weight (BMI 18.5 - 24.9) & 831 & 86.6 \\
\hline & 5) Get enough sleep (7 - 8 hours $)^{*}$ & 619 & 64.5 \\
\hline & 6) Regular exercise ${ }^{\star}$ & 383 & 39.9 \\
\hline & 7) Do not eat between meals & 177 & 18.4 \\
\hline \multirow[t]{3}{*}{ M-HPI } & 8) Balanced diet & 853 & 88.9 \\
\hline & 9) Do not work over 9 hours per day & 467 & 48.6 \\
\hline & 10) Do not feel much subjective stress & 408 & 42.5 \\
\hline \multirow[t]{6}{*}{ HLI } & 11) Always take care not to catch a cold & 917 & 95.5 \\
\hline & 12) Active in adopting useful health information in daily lifestyle & 904 & 94.2 \\
\hline & 13) Properly regulate life rhythm & 863 & 89.9 \\
\hline & 14) Remain sociable with enjoyment & 854 & 89.0 \\
\hline & 15) Usually cook food for myself and my family & 825 & 85.9 \\
\hline & 16) Try consciously to walk and use stairs & 767 & 79.9 \\
\hline
\end{tabular}

B-HPI includes 7 practices as shown in Nos. 1, 2, 3, 4, 5, 6, and 7. M-HPI includes 8 practices as shown in Nos. 1, 2, 3, 5, 6, 8, 9, and 10. ${ }^{*}$ overlapping practices in B-HPI and M-HPI.

in the groups of $16-25$ years and $\geq 26$ years $(\mathrm{p}<0.001)$ and that the desirable health practices of "Balanced diet" and "Usually cook food for myself and my family" were performed in a significantly smaller number of respondents in the group of $\leq 5$ years than in the other groups $(\mathrm{p}<0.001)$.

The desirable practice of "Get enough sleep ( 7 - 8 hours)" was performed in a significantly greater number of respondents in the groups of $\leq 5$ years and $6-15$ years than in the groups of $16-25$ and $\geq 26$ years $(p<0.001)$. The number of respondents in the group of $16-25$ years who performed the desirable practice of "Do not work over 9 hours per day" was significantly greater when compared with the groups of $16-25$ years and $\geq 26$ years $(\mathrm{p}<0.001)$ (Table 4$)$.

\subsection{Correlation between Public Health Nurses' Healthy Lifestyle Habits and Length of Experience}

The correlation coefficient between the length of experience and each assessment tool was -0.04 for B-HPI, -0.03 for M-HPI, and 0.13 for HLI $(\mathrm{p}<0.01)$. None of the assessment tools correlated with the length of experience (Table 5).

\section{Discussion}

\subsection{Representativeness of the Survey Data for the Population}

The number of subjects included in this survey accounted for about a quarter of 
Table 4. Daily lifestyle of public health nurses analyzed by years of PHN experience $(\mathrm{N}=960)$.

\begin{tabular}{|c|c|c|c|c|c|c|}
\hline & \multirow[b]{2}{*}{ Health practice indices } & \multicolumn{4}{|c|}{ Years of PHN experience } & \multirow[b]{2}{*}{$p$ value } \\
\hline & & $\begin{array}{c}5 \text { years or less } \\
n=179\end{array}$ & $\begin{array}{c}6-15 \text { years } \\
\mathrm{n}=235\end{array}$ & $\begin{array}{c}16-25 \text { years } \\
n=267\end{array}$ & $\begin{array}{c}26 \text { years or more } \\
\mathrm{n}=279 \\
\mathrm{~N}(\%)\end{array}$ & \\
\hline \multirow[t]{14}{*}{ B-HPI } & 1) Do not smoke* (yes) & 174 & 227 & 263 & 271 & 0.576 \\
\hline & & 97.2 & 96.6 & 98.5 & 97.1 & \\
\hline & 2) Moderate or no alcohol consumption* (yes) & 163 & 215 & 250 & 268 & 0.105 \\
\hline & & 91.1 & 91.5 & 93.6 & 96.1 & \\
\hline & 3) Have daily breakfast* (yes) & 155 & 216 & 254 & 268 & $<0.001$ \\
\hline & & 86.6 & 91.9 & 95.1 & 96.1 & \\
\hline & & 160 & 203 & 230 & 238 & 0.647 \\
\hline & 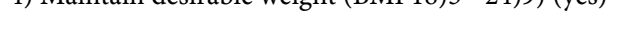 & 89.4 & 86.4 & 86.1 & 85.3 & \\
\hline & 5) Get enough sleep (7 - 8 hours)* (yes) & 136 & 178 & 151 & 154 & $<0.001$ \\
\hline & & 76.0 & 75.7 & 56.6 & 55.2 & \\
\hline & 6) Regular exercise* (yes) & 81 & 86 & 97 & 119 & 0.138 \\
\hline & & 45.3 & 36.6 & 36.3 & 42.7 & \\
\hline & 7) Do not eat between meals (yes) & 38 & 40 & 40 & 59 & 0.193 \\
\hline & & 21.2 & 17.0 & 15.0 & 21.1 & \\
\hline \multirow[t]{6}{*}{ M-HPI } & 8) Balanced diet (yes) & 141 & 209 & 240 & 263 & $<0.001$ \\
\hline & & 78.8 & 88.9 & 89.9 & 94.3 & \\
\hline & 9) Do not work over 9 hours per day (yes) & 89 & 141 & 124 & 113 & $<0.001$ \\
\hline & & 49.7 & 60.0 & 46.4 & 40.5 & \\
\hline & 10) Do not feel much subjective stress (yes) & 79 & 92 & 119 & 118 & 0.626 \\
\hline & & 44.1 & 39.1 & 44.6 & 42.3 & \\
\hline \multirow[t]{12}{*}{ HLI } & 11) Always take care not to catch a cold (yes) & 168 & 223 & 255 & 271 & 0.381 \\
\hline & & 93.9 & 94.9 & 95.5 & 97.1 & \\
\hline & 12) Active in adopting useful health information & 164 & 227 & 251 & 262 & 0.196 \\
\hline & in daily lifestyle (yes) & 91.6 & 96.6 & 94.0 & 93.9 & \\
\hline & 13) Properly regulate life rhythm (yes) & 157 & 216 & 239 & 251 & 0.564 \\
\hline & & 87.7 & 91.9 & 89.5 & 90.0 & \\
\hline & 14) Remain sociable with enjoyment (yes) & 162 & 211 & 228 & 253 & 0.180 \\
\hline & & 90.5 & 89.8 & 85.4 & 90.7 & \\
\hline & 15) U & 119 & 204 & 238 & 264 & $<0.001$ \\
\hline & & 66.5 & 86.8 & 89.1 & 94.6 & \\
\hline & 16) Try consciously to walk and use stairs (yes) & 141 & 189 & 207 & 230 & 0.525 \\
\hline & & 78.8 & 80.4 & 77.5 & 82.4 & \\
\hline
\end{tabular}

B-HPI includes 7 practices as shown in Nos. $1,2,3,4,5,6$, and 7. M-HPI includes 8 practices as shown in Nos. 1, 2, 3, 5, 6, 8, 9, and 10. *overlapping practices in B-HPI and M-HPI. 
Table 5. Correlation between public health nurses' healthy lifestyle habits and length of experience $(\mathrm{N}=960)$.

\begin{tabular}{ccccc}
\hline & B-HPI & M-HPI & HLI & \\
\hline Years of PHN experience & -0.04 & -0.03 & 0.13 & $* *$ \\
\hline
\end{tabular}

${ }^{* *} p<0.01$. Correlation coefficient represents Spearman's rho (two-tailed).

the population and they were not biased in terms of age and affiliation. These subjects are considered to represent the population.

\subsection{Actual Status of Public Health Nurses' Healthy Lifestyle Habits}

1) Characteristics of public health nurses' healthy lifestyle habits

Eleven desirable health practices of the 16 were performed by about more than $80 \%$ of respondents, indicating that the healthy lifestyle habits of public health nurses are generally good. However, there were some practices such as eating between meals, having little physical activity, and not having enough rest or sleep, that need to be improved.

The desirable health practice performed by the greatest number of respondents was "Do not smoke". This survey revealed that $97.4 \%$ of respondents did not have smoking habits. Considering that $81.8 \%$ of men and women aged $\geq 20$ years in Japan are non-smokers, public health nurses are good with respect to non-smoking habits [12]. Causal relationships between smoking habits and various diseases including cancers and cardiovascular diseases have been globally pointed out, and measures to reduce unfavorable effects of smoking on health have been increasingly strengthened [13]. Public health nurses play significant roles in promoting measures for tobacco control such as improvement of smoking habits and establishment of environment contributing to prevention of passive smoking. In 2003, the Japanese Society of Public Health announced its "Declaration of Action Plans for Realization of a Tobacco Free Society" and as one of its basic policies, has encouraged the members belonging to the Society to quit smoking [14]. The Japan Society of Ningen Dock (note that the Japanese term "Ningen Dock" means "comprehensive medical examination") aims to have all members being non-smokers, and sets one of the qualifications for specialists or designated physicians for Ningen Dock at being a non-smoker. The Society thus defines its position to request the professional specialists engaged in disease prevention to be non-smokers [15]. From this perspective, public health nurses should also be non-smokers and the smoking practice of public health nurses cannot be regarded as best.

For HLI, the total score was high, and examination of its individual practices revealed that high proportions of respondents performed desirable practices related to health awareness and sense of values for health. For the other assessment tools, however, the desirable health practices of "Do not eat between meals", "Regular exercise", "Do not feel much subjective stress", and "Do not work over 9 hours per day" were performed by smaller numbers of respondents. 
For the practice of "Do not eat between meals" in B-HPI, in particular, as small as less than $20 \%$ of all respondents performed this desirable health practice. The background of this may be the fact that the duties of public health nurses have increased in levels and become complicated, leading to longer working hours, reducing their hours engaged in health and welfare activities, and increasing their involvement in deskwork such as communication among staff members and clerical works. It is presumed that these circumstances are likely to allow public health nurses to eat between meals. Following the practice of "Do not eat between meals", the desirable health practice performed by the next smallest number of respondents was "Regular exercise" in B-HPI. The desirable health practice of "Try consciously to walk and use stairs" in HLI was performed by about $80 \%$ of respondents, although this proportion was lowest among the practices questioned in HLI. These results suggest that even public health nurses are hard to have exercise habits or have adequate physical activity, when compared with the other llifestyle practices. The background of this may be the fact that their situations do not give much pressure to them so that they have no choice but to exercise, making them less motivated to exercise in their daily lives. This may be true when looking at the desirable health practice of "Maintain desirable weight (BMI 18.5 - 24.9)" in B-HPI that was performed by $86.6 \%$ of respondents. The men and women aged $\geq 20$ years in Japan have less desirable habits of regular physical exercise, when compared with the other lifestyle practices. The similar tendency is found for the public health nurses in Japan.

2) Characteristics of public health nurses' healthy lifestyle habits by length of experience

Analysis by the length of experience revealed that the group of 6 - 15 years had more desirable health practices performed by more respondents than the other groups. This group is estimated to have more individuals who raise children and it was therefore considered that child-raising contributes to keeping their regular routine.

It was observed that the younger group with $\leq 5$ years of career experience needs to improve the following: not eating breakfast, nutritional balance, and few opportunities to cook in daily lives. This may be explained by low levels of awareness for their own health and the fact that they do not have many opportunities to do household chores.

For the groups of $\geq 16$ years, it was found that sleeping hours and working hours need to be balanced better. This age generation is estimated to have many individuals who are in managerial positions, suggesting a relation to working hours.

3) Relationship between lifestyle practices and length of experience

No correlation was observed between the total score of each assessment tool and the length of experience. This means that only accumulating their career experience of public health nursing does not always lead to shaping up of their 
own healthy lifestyle practices.

4) Suggestion for healthy lifestyle habits of public health nurses in Japan

In light of the above, the public health nurses in Japan have highly health awareness and are proactive in maintaining their health in good condition, although the circumstances in which they are now sometimes inhibit them from keeping desirable health practices. It is therefore required to improve their circumstances and in addition, the significance of improving lifestyle habits needs to be highlighted from the ethical viewpoint of professional occupation and from the perspective of improving professional skills, so as to give public health nurses motivation to have desirable health practices.

Specifically, the younger group needs to be motivated to change their behavior regarding the practices of not eating breakfast, nutritional balance, and few opportunities to cook in daily lives, while the group in administrative position needs to be motivated to change their behavior in terms of sleeping hours and working hours. Experience through involvement in daily living activities such as housekeeping is necessary for younger public health nurses to give shape to their guidance on health. It is therefore necessary, from the viewpoint of improving professional skills, to show them the importance of their involvement in daily household chores. In addition, since this research has demonstrated that having a desirable healthy lifestyle does not depend on the length of experience, the following point needs to be highlighted continuously, starting in the phase of fundamental education for public health nursing: it is necessary and significant for public health nurses, who are professionals engaged in giving health guidance, to organize their own lifestyle practices.

\subsection{Limitations of This Research and Future Issues to Be Addressed}

This research has clarified the actual status of healthy lifestyle practices of public health nurses. However, since we did not set survey parameters with which we could investigate background factors for these practices, including among others family situation, details of work, and whether or not they are currently raising children, and did not intend comparison with the other professions, we did not obtain data sufficiently enough to evaluate future direction, which is the limitation of this research. In the future, background factors for the practices that were determined by this research to require improvement need to be clarified in more detail such that public health nurses can have more desirable health practices and contribute to high-quality public health nursing. It is also necessary to improve the system under which public health nurses can provide support to care receivers while taking the professional responsibility.

\section{Conclusions}

1) This survey has demonstrated that the healthy lifestyle practices of public health nurses are generally good. 
2) However, there were some practices such as eating between meals, having little physical activity, and not having a good rest/sleep, that need to be improved.

3) Analysis by the length of experience revealed that the younger public health nurses with $\leq 5$ years of experience need to improve their practices related to meals and nutritional status, and the generation with $\geq 16$ years of experience in which many individuals are in managerial positions need to improve working hours.

4) This survey has clarified that the healthy lifestyle practices of public health nurses did not correlated with their length of experience, indicating that the healthy lifestyle practices are not intensified by the accumulated career experience as public health nurses.

5) In the future, further survey is required to investigate background factors for the practices that were determined by this research to require improvement, so as to provide specific strategies for public health nurses to practice healthy lifestyle habits.

\section{References}

[1] International Council of Nurses (2012) The ICN Code of Ethics for Nurses. http://www.icn.ch/who-we-are/code-of-ethics-for-nurses/

[2] Japan Nursing Association (2003) The Japan Nursing Association Code of Ethics for Nurses. (In Japanese).

https://www.nurse.or.jp/nursing/practice/rinri/pdf/rinri.pdf

[3] Morishita, Y., Miki, A., Okada, M., Ando, Y., Muto, S., Osada, T. and Kusano, E. (2014) Exercise Habits of Family Doctors Affect Exercise Instruction for CKD Patients. The Japanese Journal of Nephrology, 56, 309. (In Japanese)

[4] The JMA's Project Committee on Health Support for Hospital-Employed Physicians (2009) Questionnaire Survey Report on the Current State of Health of Hospital-Employed Physicians and How to Support Them. (In Japanese) http://dl.med.or.jp/dl-med/teireikaiken/20090902_32.pdf

[5] Nakao, H., Kobayashi, T. and Sinagawa, S. (2003) Relationships between Work-Related Stress, Depression Symptoms and Lifestyle of Nurses. Journal of Yamaguchi Prefectural University, 7, 25-31. (In Japanese)

[6] Japan Nursing Association (2015) Basic Survey Report on the Foundation of Public Health Nurse's Activities. (In Japanese) http://www.nurse.or.jp/home/publication/pdf/senkuteki/2015/26-katsudokiban.pdf

[7] Nakano, K., Yabe, J. and Yasumura, S. (2006) Health Practice and Total Mortality among Middle-Aged and Elderly Residents in Sukagawa, Japan. Japan Journal of Public Health, 53, 329-337. (In Japanese)

[8] Hayakawa, M. and Inoue, K. (2008) Relationship between Breslow Health Index and Health Risk Disease Risk Factors or Dietary Habits. Journal of Health and Welfare Statistics, 55, 1-8.

[9] Belloc, N.B. and Breslow, L. (1972) Relationship of Physical Health Status and Health Practices. Preventive Medicine, 1, 409-421.

https://doi.org/10.1016/0091-7435(72)90014-X

[10] Morimoto, K. (2003) What Is the Morimoto's 8 Practices? Obesity and Diabetes, 2, 
79-81. (In Japanese)

[11] Okamoto, R., Iwamoto, S., Shiomi, M. and Kotera, S. (2010) Creation of a Professional Development Scale for Public Health Nurses and Investigation of Its Reliability and Validity. Japan Journal of Public Health, 64, 355-365.

[12] Ministry of Health, Labour and Welfare (2013) Outline of National Health Nutrition Survey Results. (In Japanese)

http://www.mhlw.go.jp/file/04-Houdouhappyou-10904750-Kenkoukyoku-Gantaisa kukenkouzoushinka/0000106403.pdf

[13] Investigative Commission of Effects of Smoking on Health (2016) Smoking and Health: Report on Effects of Smoking on Health. (In Japanese)

http://www.mhlw.go.jp/stf/shingi2/0000135586.html

[14] Japanese Society of Public Health (2003) Declaration of Behavior toward Realization of Tobacco-Free Society. (In Japanese) http://www.jsph.jp/activity.php?no=6

[15] Hasegawa, K., Ozaki, Y., Komiyama, M., Takahashi, Y. and Nakamura, M. (2016) Study on the Positioning of Smoking Cessation Recommendation in Clinical Practice Guidelines. Japanese Journal of Public Health, 63, 758-768. 